\title{
Rope-pump System Modelling using Renewable Power Combinations
}

\author{
Cai Williams ${ }^{1}$, Andrew Beattie ${ }^{1}$, Tim Parker ${ }^{1}$, Jo Read ${ }^{1}$, Julian D. Booker ${ }^{1 *}$ \\ ${ }^{1}$ University of Bristol, Bristol, UK \\ *Corresponding author. Tel: +44 117331 5905, Fax: +44 117929 4423, E-mail: j.d.booker@bristol.ac.uk
}

\begin{abstract}
Rope-pumps are a highly successful method of lifting water by hand in developing countries. The primary aim of this work was to develop a validated methodology to decide the most cost effective renewable power sources in order to fully automate the operation of the rope-pump for given well depth, volume of water required and environmental conditions in the proposed installation location. The renewable energy sources considered were a $150 \mathrm{~W}$ photovoltaic (PV) panel and a 100W wind turbine, either used in isolation or in combination with a battery and motor, or direct drive to a motor, providing five viable systems for further consideration. All system elements and the rope-pump itself were fully characterised through experimental testing. Computer-based simulations incorporating environmental conditions for Lilognwe, Malawi, were used to provide a 15 year lifecycle analysis. Results show that the use of PV powered system can deliver water reliably, at the lowest cost. For validation purposes, each rope-pump system was also analysed with the environmental conditions found in Bristol, UK providing comparison results, indicating the approach is systematic and rigorous enough to provide an effective decision making tool for the installation of rope-pumps anywhere, provided environmental data is available.
\end{abstract}

Keywords: Rope-pump, renewable power, system modelling, system selection.

\section{Introduction}

The rope-pump is a very simple type of water lifting device. The almost intuitive design is known by many other names including the paternoster (after the beaded prayer chain it resembles), liberation or rope-and-washer pump. It is a relatively recent development of the ancient chain-and-washer pump, which dates back two thousand years to feudal China [1]. In the 1980s the basic design was developed by numerous individuals [2, 3], taking advantage of low cost and versatile modern plastics to produce the modern rope-pump design, shown schematically in Fig.1. The rope-pump consists of a continuous loop of rope with plastic pistons spaced evenly along its length. When the rope is pulled up through the rising-main by a drive wheel located at ground level, the close fit of the pistons in the cylinder draws water up to a height of $30 \mathrm{~m}$ potentially.

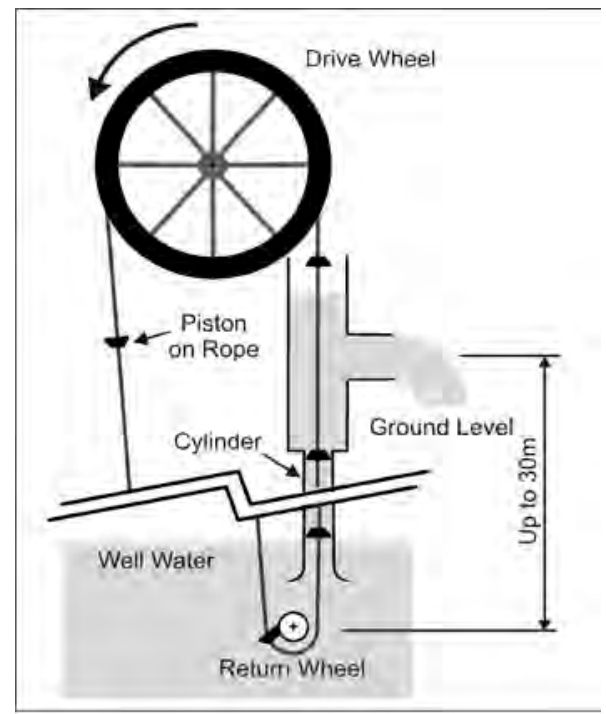

Fig.1. Schematic of a Rope-pump Powered Manually using a Drive Wheel. 
The hand powered rope-pump has been highly successful across Africa and South America mainly due to attributes such as a high achievable head, low starting torque, low installation cost, ease of manufacture and minimal maintenance. These attributes identify the rope-pump as the most appropriate type of pump for automation, providing the remaining system components for automation still allow water to be delivered reliably at low cost. An affordable automated pump would allow a greater amount of water to be extracted than would be possible by hand alone, and this has many implications societally and economically for its users in developing countries. The extra water could be used to improve levels of sanitation and increase crop yields. This in turn would improve nutritional levels and provide a potential income from the sale of excess produce. It would also free up the time of users, which would otherwise be spent manually lifting limited amounts of water. This time could then be used for education and other income generating activities [4]. Various types of power supply for the rope-pump have previously been explored in order to replace manual operation, including: water wheel, pack animal, internal combustion engine and wind-turbine. This research aimed to simulate the performance of a range of automated systems with two renewable energy power sources (PV panel and wind turbine) in order that an economically viable rope-pump solution can be selected for any specific location and given set of environmental conditions.

\section{Methodology}

Economic, social and environmental factors associated with technical hardware prove to be crucial to the success or failure of the final rope-pump systems. Frequent maintenance and additional control systems required are likely to make the system impractical in locations where the necessary resources are unlikely to be available. The importance of a simple system, with a minimal demand on local expertise and supply chains and one that is appropriate to both the hydrological, geographical and social environment is crucial, a point stressed by industrial contacts and made clear from reviewing existing rope-pump systems.

A literature review, in combination with a dialogue with representatives of Solar-Aid (the main industrial contact on the project) identified the requirements of an automated rope-pump system, which were then summarised in a product design specification (PDS). Five system configurations capable of fulfilling this PDS were identified through a team-based exercise with all project stakeholders. These systems are shown schematically in Fig.2, and are a) direct connection of the motor to a PV panel; b) direct connection of the motor to a wind turbine; c) connection of the motor to a PV panel via a battery; d) connection of the motor to a wind turbine via a battery; and e) connection of both a PV panel and a wind turbine to the motor via a battery. The common component of all the system configurations devised is a suitably geared motor, but it would still be possible to decouple the motor from the ropepump drive axle and provide manual operation through a hand-crank.

First, a theoretical force model for the rope-pump was developed based on a complete analysis of the frictional loads and energy flows present within the rope-pump. This could then define the electrical power and speed (gearing) requirements of the motor drive. Force and flow models were investigated empirically using a custom built motor driven rope-pump rig, designed to measure the rope tension, rope velocity and the discharge flow-rate, for two different pipe diameters and a range of heads up to $8 \mathrm{~m}$. The force model developed was found to be significantly more accurate than models proposed in previous literature, and the dependency of the flow-rate of the rope-pump on head and rising-main diameter was empirically confirmed to match an improved version of the model $[5,6]$. The comprehensive treatment and analysis of frictional loads and energy flows within the rope-pump produced a key component of the system model performance model. 
The remaining specific characteristic parameters of all system components were identified empirically from experimental testing; designed and built to accurately simulate the duty cycles of the components. The renewable energy power sources were chosen as a 150W PV panel (two RSM-75 from Shell Solar) and a 100W wind turbine with an axial flux generator, hand-built Hugh Piggott turbine type [7]. These system components were chosen due to availability and comparable (full) power rating to that of a human male, assuming a working duration of one hour. The wind turbine was fully characterised at different load conditions and wind speeds using a wind-tunnel providing new performance data for this turbine. Models of the motor, battery and PV panel were also identified and supported along with the turbine by empirical observations of their characteristics. The complete solar powered systems were tested under the local environmental conditions in Bristol, UK, but due to limiting wind speeds and radiation from the sun, the combined power sources had to be replicated using a power supply unit. A detailed description of the governing analytical equations and experimental characterisation for all system components is provided in [5] and [8].

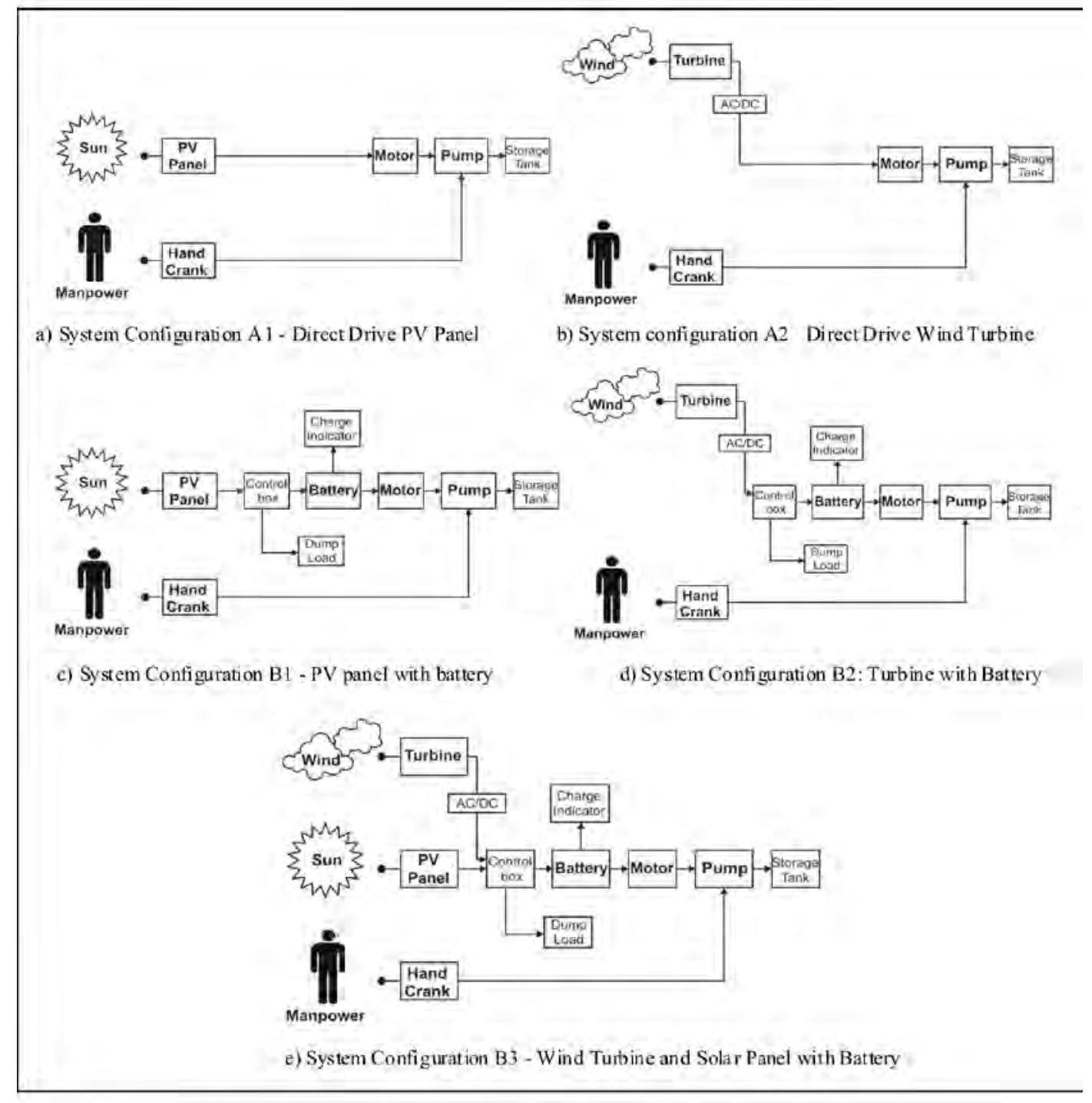

Fig.2. Five Automated Rope-pump System Configurations Considered for Simulation Studies.

From the comprehensive rope-pump system model, two computer programmes using MATLAB programming software were coded in order to investigate more efficiently a wide range of operational requirements for those systems with a battery and those without a battery, 
as the computational stages are quite different for each. The computer programmes are provided in flowchart form (for one time-step) in Fig.3a) for those system configurations that use a battery, and Fig.3b) for those that do not i.e. directly driven by a motor, respectively. Together, these programmes are able to replicate the complete rope-pump system in direct drive or battery configurations, utilising a PV module and/or wind turbine as power inputs.

The PV panel model is based on the characteristic equations, and only requires inputs which are available on standard datasheets as this allows for easy comparison of alternative modules within the system. The wind turbine was modelled by directly uploading results from the turbine characterisation testing into the computer program. The program inputs are the independent local parameters (such as head and local weather data) and parameters which determine the size of the system (such as pipe diameter and number and characteristics of solar panels). This allows for the flow rate, and therefore the water volume lifted, to be estimated based on the capital cost available, as capital cost was identified as the a key differentiating requirement in the PDS.

A rigorous test regime showed the flow rates predicted by the computer model to be accurate to within $7 \%$ compared to the results from the experimental rope-pump. This is considered acceptable considering the unavoidable sources of error which would occur were the computer program to be used to size rope-pumps for use in the field. There are considered to be two major and unavoidable sources of error: firstly, the variation of local weather conditions from the average conditions used as program inputs will lead to the available power differing from the predicted values. For example, a decrease in the insolation available by $10 \%$ leads to a $4 \%$ decrease in the volume of water lifted for a direct drive PV powered system. Secondly, the empirical values derived for the pump and motor in the characterisation stage will not be identical for each rope-pump built. This is particularly true of the friction coefficient over the bottom guide, for which an increase from $1 \mathrm{~N}$ to $10 \mathrm{~N}$ leads to a $10 \%$ decrease in the volume water lifted for a head of $10 \mathrm{~m}$ for a given internal rising-main diameter.

\section{Results}

The town of Lilongwe, Malawi and the city of Bristol, UK, are used as case examples for results analyses. Lilongwe is where the main industrial contact of the project, Solar-Aid, is based. Bristol is used to provide comparison data for presentation of the results and in order to demonstrate the robustness of the simulation software for a very different set of environmental conditions. The rope-pump is to be used to lift 1 to $10 \mathrm{~m}^{3}$ of water per day from a well $10 \mathrm{~m}$ deep. This is a volume that is more than can be reasonably lifted by hand and a suitable amount for a typical small rural institution such as a school or hospital in Malawi. The environmental data used in the simulations were taken from a number of online sources [9-11]. 

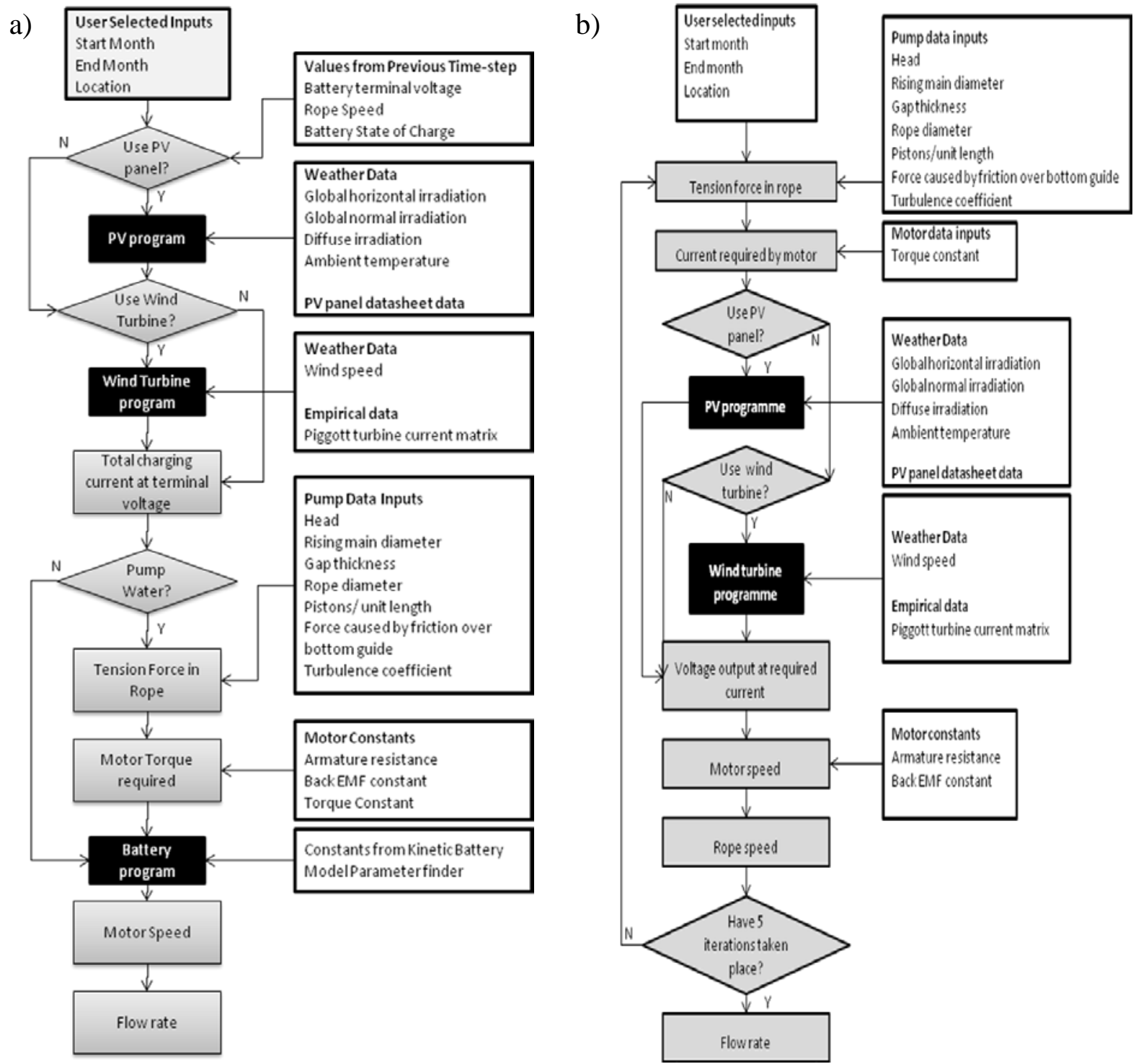

Fig.3. Simulation Flowcharts for Automated Rope-pump Configurations, a) battery systems, b) direct drive systems.

A 15 year life-cycle analysis was carried out for each of the five system configurations, including an additional variant of the direct driven rope-pump using a PV panel, called "A1tilt”, where the PV panel is manually oriented towards the direction of the sun periodically. The results of this life-cycle analysis for both Lilongwe and Bristol locations are shown in Fig.4. Where wind velocities are sufficient, the direct drive wind turbine rope-pump system has the potential to deliver water for the lowest cost $\left(0.03 \mathrm{US} \$ / \mathrm{m}^{3}\right.$ from $\left.10 \mathrm{~m}\right)$ in Lilongwe. However, the starting speed of the tested wind turbine was $3 \mathrm{~m} / \mathrm{s}$, and makes this wind turbine component unsuitable for use in Malawi. The cost per $\mathrm{m}^{3}$ of water lifted is capped at $\$ 0.14 / \mathrm{m}^{3}$ for all rope-pump system configurations, and as Fig.4 shows, those systems using wind turbines in Lilongwe are the most costly. The use of a direct drive PV powered rope-pump system is then preferable as indicated by the low cost of A1. It is estimated that a direct drive PV system in Malawi weather conditions can deliver water at a cost of $0.05 \mathrm{US} \$ / \mathrm{m}^{3}$, again from 10m well. This cost can be reduced further with the A1-tilt system, although this system is not fully automated. In all cases the use of a battery was found to increase the cost per cubic meter of water lifted despite the increased volume of water delivered. For the PV powered rope-pump system, the cost was increased by $20 \%$, for example. 


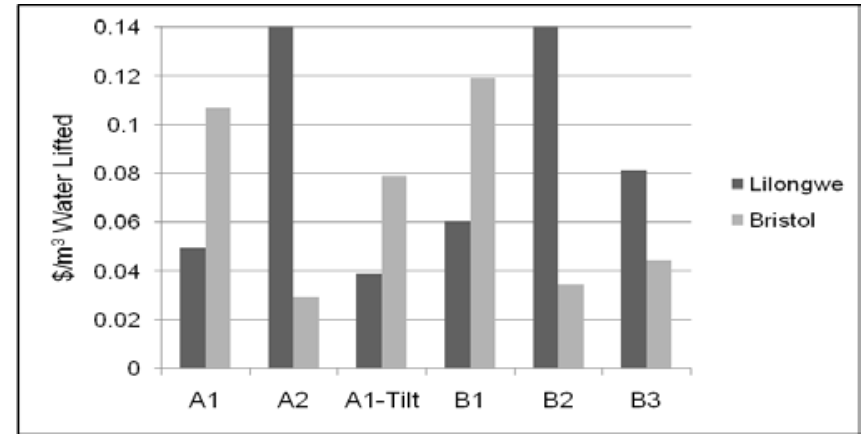

Fig.4. Cost of Water Lifted for Each Rope-pump Configuration in Lilongwe, Malawi and Bristol, UK.

Further results from the simulations are shown in Fig.5, where a daily volume of water in $\mathrm{m}^{3}$ is provided for given inputted environmental data for a calendar year. These results are cost independent, and are purely performance based. Again, the solely wind turbine powered ropepump systems A2 and B2 are determined as non-viable configurations for Lilognwe, as they do not appear on this chart at all. Systems B1 and B3 seem competitive in terms of water lifted, but B3 uses the wind turbine, and therefore it does not contribute to the system power due to a $3 \mathrm{~m} / \mathrm{s}$ starting wind speed, and should be disregarded. Similarly, B1 uses a battery and therefore is more costly overall for initial investment and long-term servicing, as previously estimated.

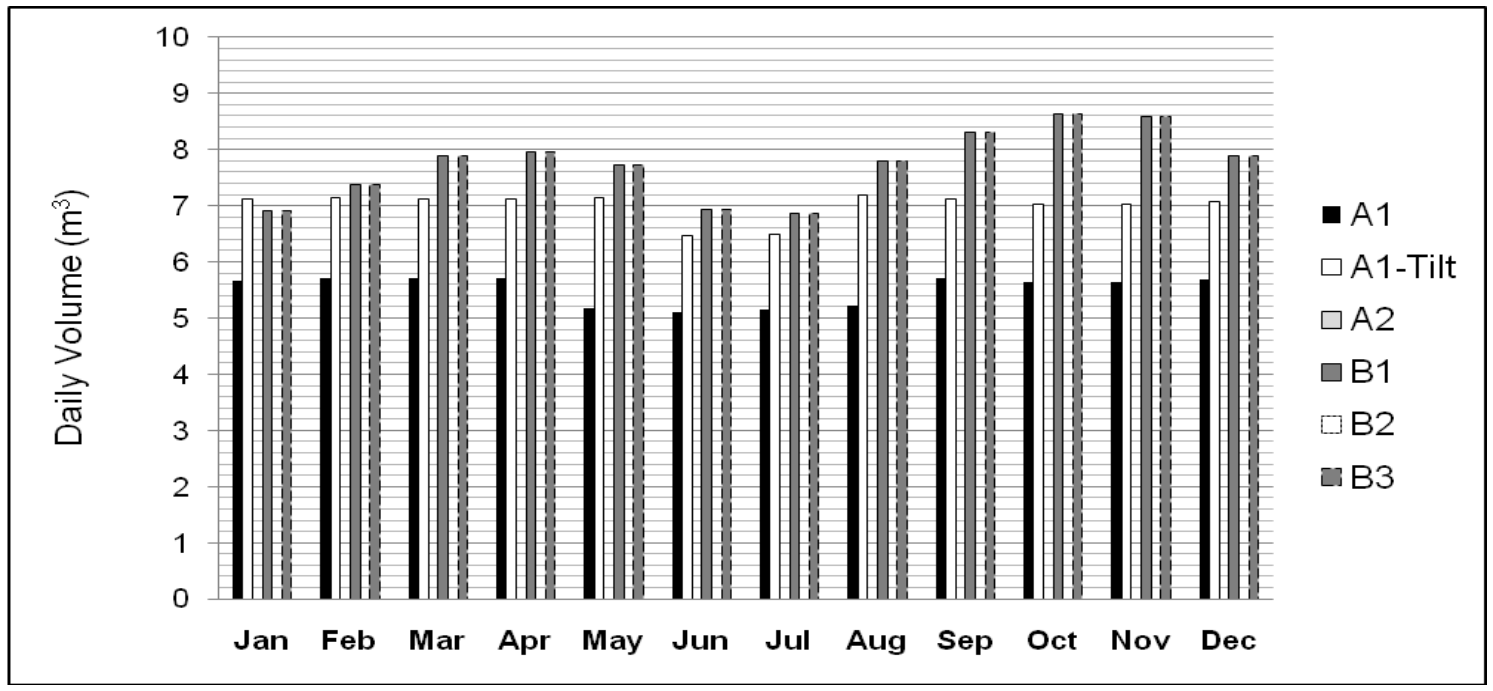

Fig.5. Daily Volume of Water from the Different Rope-pump Configurations for Lilongwe, Malawi Location (wind speeds in Lilongwe are lower than the cut in wind speeds for the tested turbine and so configurations A2 and B2 lift no water).

The results for Bristol are demonstrative of the range of location conditions that the simulation software can accommodate, with the only requirement of satisfactory data sets used for cost and environmental parameters. Overall, the results are very different to Lilongwe, as expected. All system configurations are technically viable at some part of the year, as indicated by Fig.6. A direct drive (A2) or battery powered (B2) wind turbine ropepump configurations are the most cost effective as shown originally in Fig.4. 


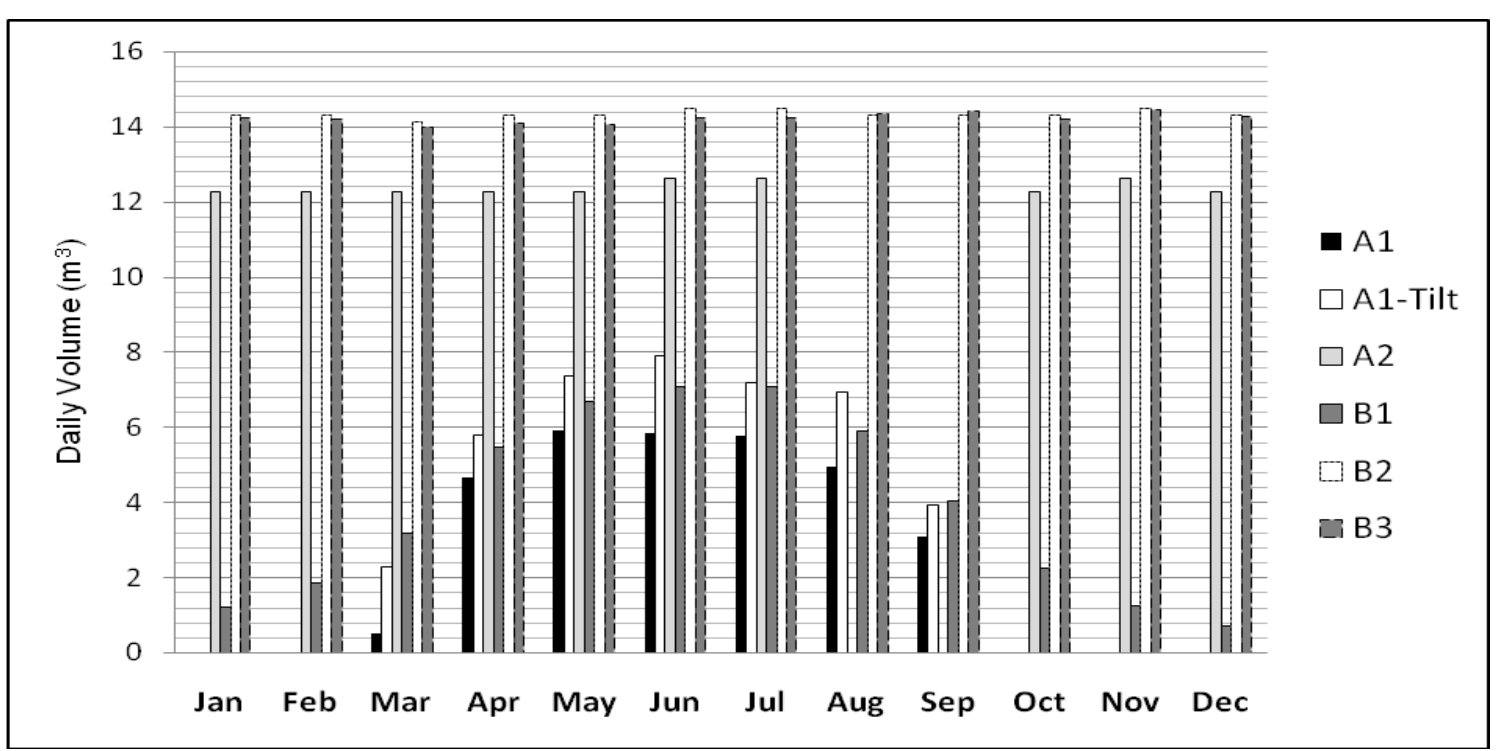

Fig.6. Daily Volume of Water from the Different Rope-pump Configurations for Bristol, UK Location.

\section{Conclusions}

Fully parameterised software, together with scalable hardware for physical testing of a variety of rope-pump systems has been produced in order to provide a decision making tool to select the most appropriate combination of system elements for technical and economic viability. The results shown confirm the simulation software has the flexibility to be applied to a variety of environments, duty cycles and rope-pump delivery requirements. An improved model for the rope-pump mechanical loads and flow-rates enables detailed specifications of sub-systems based around the rope-pump to be made, when previously a significant degree of trial and error was required. The method has been applied to different areas of the world to show the acceptability of other systems given their environmental data.

The use of a battery as the primary load on the PV module or wind turbine allowed for the efficient matching of the IV curves of the power source with the IV curves of the load, leading to an average of $40 \%$ more water pumped per annum for PV powered systems. However, the inherently short life-span of the battery leads to high capital and component replacement costs which lead to the cost per litre of water lifted being an average of $20 \%$ higher for systems utilising a battery than for the direct drive rope-pump systems. In locations where water source reliability is a concern, a reservoir should be used instead of storing energy in a battery, if installation costs permit. There has been considerable interest in the solar powered rope-pump for use in countries that have high-average sunshine levels, since its conception in 2007 [4]. The simulation has confirmed that a battery is not necessary for such locations. Based on other findings of the project, the possibility of integrating a wind turbine with a rope-pump may be given greater investigation for certain locations for installation, but requires a range of alternative turbine types to be evaluated. For example, the use of a small vertical axis wind turbine may offer a promising alternative to the one tested in this study.

There is potential for the computer program to be used by individuals and companies charged with the design and distribution of rope-pump systems. For this to be possible, the program would need to be loaded with weather data for a wide range of locations, and with power curves for a selection of available wind turbines. The process of selecting a PV module could also be improved if the program were linked to an available database of PV modules, such as that compiled by Sandia [12] removing the need to input a large amount of data from 
datasheets. The program would be of most use in the early system design stages, to carry out feasibility studies for a number of system configurations. This will allow the user to determine the most suitable system for the location, which could then be designed in detail, with consideration given to the realities of component sourcing and maintenance. The modular nature of the program makes it possible to add additional 'modules'. Any component which can be fully characterised could be added. A suitable module would be a small grain mill: an item commonly used in developing countries which requires large amounts of man power to operate and has the potential to be powered by alternative sources. There is also potential for adding additional power source modules, for example, a diesel engine.

\section{Acknowledgements}

The authors would like to thank. Mark O’Riordan from Partners in Development, Bobby Lambert, Cardiff University and Solar-Aid, the project's industrial contact.

\section{References}

[1] P. Fraenkel and J. Thake, Water Lifting Devices: a handbook for users and choosers, Rugby: Intermediate Technology Publications Ltd, $3^{\text {rd }}$ Ed., 2006.

[2] R.A. Lambert, How to Build a Rope-and-Washer Pump, Intermediate Technology Design Group, London, 1990.

[3] J.H. Alberts, The Rope-Pump: an example of technology transfer, Waterlines, 22(3), 2004, pp. 22-25.

[4] R.A. Lambert, Jumemaji: Solar Pumping for Sustainable Food Production Concept Paper, 2007 [Available from: bobby@bobbylambert.eul, 5 ${ }^{\text {th }}$ July 2007].

[5] A. Blanken, Measurements and Analysis on the Performance of the Rope-pump, University of Technology, The Netherlands, 2009 [http://www.msabi.org/docs/ropepump, viewed online 08/12/10].

[6] P. T. Smulders and R.P.P. Rijs, A Hydrodynamic Model of the Rope-pump, Veldhoven, The Netherlands, 2006 [http://www.arrakis.nl/reports/060923_Ropepump_SmuldersRijs_lr.pdf, viewed online 08/12/10].

[7] H. Piggott, A Wind Turbine Recipe Book [http://www.scoraigwind.com, viewed online 13/12/10].

[8] A. Beattie et al, Rope-pump System Modelling using Alternative Power Combinations, UK, 2009 [http://www.msabi.org/docs/ropepump, viewed online 08/12/10].

[9] European Commission, Photovoltaic Geographical Information System (PVGIS) [http://re.jrc.ec.europa.eu/pvgis, viewed online 08/12/10].

[10]R. Hoare, World Climate [http://www.worldclimate.com, viewed online 08/12/10].

[11]The Weather Network, Statistics: Chitedze, Malawi [http://www.theweathernetwork.com/index.php?product=statistics\&pagecontent=C0179, viewed online 08/12/10].

[12] Sandia National Laboratories, Photovoltaic System Research and Development [http://photovoltaics.sandia.gov, viewed online 08/12/10]. 